\begin{tabular}{|c|c|}
\hline Postprint Version & Final draft post-refereeing \\
\hline Journal website & http://www.springerlink.com/content/1661-8564 \\
\hline PubMed link & http://www.ncbi.nlm.nih.gov/pubmed/21901332 \\
\hline DOI & $10.1007 / \mathrm{s} 00038-011-0297-\mathrm{x}$ \\
\hline
\end{tabular}

\title{
The prevalence and management of cardiovascular risk factors in immigrant groups in Switzerland
}

\author{
Pedro Marques-Vidal ${ }^{1}$; Peter Vollenweider ${ }^{2}$; Gérard Waeber ${ }^{2}$ and Fred Paccaud ${ }^{1}$ \\ ${ }^{1}$ Institute of Social and Preventive Medicine (IUMSP), Epalinges, Switzerland \\ ${ }^{2}$ University Hospital (CHUV), Lausanne, Switzerland
}

\section{Emails of authors}

PM-V: Pedro-Manuel.Marques-Vidal@chuv.ch

PV: Peter.Vollenweider@chuv.ch

GW: Gerard.Waeber@chuv.ch

FP: Fred.Paccaud@chuv.ch

\section{Address for correspondence:}

Pedro Marques-Vidal

Institute of Social and Preventive Medicine (IUMSP)

University Hospital and Faculty of Biology and Medicine of Lausanne

Route de la Corniche 2

1066 Epalinges

Switzerland

Phone: +4121314 7265

Fax: $\quad+41213147244$

Email: Pedro-Manuel.Marques-Vidal@chuv.ch

\footnotetext{
Abstract

Objectives: Compare the prevalence and management of cardiovascular risk factors (CVRFs) between immigrant groups and Swiss nationals.

Methods: Swiss Health Surveys (SHS, $\mathrm{N}=49,245)$ and CoLaus study $(\mathrm{N}=6,710)$. Immigrant groups from France, Germany, Italy, Portugal, Spain, former Yugoslavia, other European and other countries were defined.
} 
Results: Immigrants from Italy, Portugal, Spain and former Yugoslavia presented a higher prevalence of smoking than Swiss nationals. Immigrants reported less hypertension than Swiss nationals, but the differences were reduced when blood pressure measurements were used. The prevalence of dyslipidaemia was similar between immigrants and Swiss nationals in the SHS. When eligibility for statin treatment was assessed, immigrants from Italy were more frequently eligible than Swiss nationals. Immigrants from Italy and former Yugoslavia presented a lower prevalence of diabetes in the SHS but a higher prevalence in the CoLaus study. Most differences between immigrant groups and Swiss nationals disappeared after adjusting for age, leisure-time physical activity, overweight/obesity and education.

Conclusions: Most CVRFs are unevenly distributed among immigrant groups in Switzerland, but these differences are due to disparities in age, leisure-time physical activity, overweight/obesity and education.

Keywords: diabetes; dyslipidaemia; hypertension; immigrants; smoking; Switzerland

\section{Introduction}

Immigrants tend to present a higher risk of cardiovascular disease (CVD) than local nationals (Gadd et al. 2003), but this statement has been challenged (Kouris-Blazos 2002). Although part of these differences might be related to differing levels in sociocioeconomic status (Bos et al. 2004), some migrant groups have been shown to be either more (Bainey and Jugdutt 2009) or less susceptible (Kouris-Blazos 2002) to CVD irrespective of their risk factor levels. Several studies have also shown that management of CVD risk factors (CVRFs) is less optimal among migrants compared to nationals (Cappuccio et al. 1997; Carrasco-Garrido et al. 2007).

Switzerland has a large immigrant community of over 1.6 million people, representing more than one-fifth of the total population (Office Fédéral des Migrations (ODM) 2010). In Switzerland, immigrants from southern European countries present lower mortality rates from CVD than Swiss nationals (Wanner et al. 2000). Whether these lower CVD mortality rates among migrants in Switzerland is due to differences in socioeconomic or CVRF levels is currently unknown. Finally, the prevalence of the main CVRFs (smoking, hypertension, dyslipidaemia and diabetes) has not been studied with respect to immigrant groups in Switzerland.

In this study, we used the data from two large, population-based samples-Swiss Health Surveys and the Cohorte Lausannoise (CoLaus) study-to assess the prevalence and management of CVRFs according to nationality in Switzerland.

\section{Methods}

Two different data bases (Swiss Health Survey - SHS and CoLaus study) were used. This was due because as they complement each other regarding the methodology: the SHS is a nationwide qualitative study which collected only reported data, while the CoLaus study is a local (city of Lausanne) population-based quantitative study which measured data using 
standardized procedures. The use of two different data bases also enables to replicate and confirm the findings, thus decreasing the likelihood of bias-induced results.

\section{Colaus study}

The CoLaus Study was approved by the Institutional Ethics Committee of the University of Lausanne. The CoLaus Study is a cross-sectional study aimed at assessing the prevalence and deciphering the molecular determinants of cardiovascular risk factors in the Caucasian population of Lausanne, Switzerland.

The sampling procedure of the CoLaus Study has been described previously (Firmann et al. 2008). The inclusion criteria applied were as follows: (a) written informed consent; (b) age 35-75 years; (c) willingness to take part in the examination and donate a blood sample; and (d) Caucasian origin. Recruitment began in June 2003 and ended in May 2006. The participation rate was $41 \%$. For this study, data from non-Caucasian participants $(n=555)$, which was initially excluded from the main study but assessed the same way, were also included.

All participants attended the outpatient clinic of the University Hospital of Lausanne in the morning following an overnight fast. Data were collected by trained field interviewers in a single visit lasting approximately $60 \mathrm{~min}$.

Venous blood samples were drawn after an overnight fast, and assays were performed by the CHUV Clinical Laboratory on fresh plasma samples within 2 hours of blood collection in a Modular P apparatus (Roche Diagnostics, Switzerland). LDL-cholesterol was calculated with the Friedewald formula only if triglycerides were $<4.6 \mathrm{mmol} / \mathrm{l}$.

Blood pressure (BP) was measured three times on the left arm after at least 10 minutes of rest in a seated position using a clinically validated automated oscillometric device (Omron ${ }^{\circledR}$ HEM-907, Matsusaka, Japan) with a standard cuff, or a large cuff if arm circumference was $\geq 33$ $\mathrm{cm}$. The average of the last two BP readings was used. Measured high blood pressure (HBP) was defined as mean systolic BP (SBP) $\geq 140 \mathrm{~mm} \mathrm{Hg}$ or mean diastolic BP (DBP) $\geq 90 \mathrm{~mm} \mathrm{Hg}$ or antihypertensive medication. Reported HBP was defined as a positive answer to the question "Have you ever been told by a doctor that you have high blood pressure (hypertension)?". Antihypertensive medication was defined as a positive answer to the question "Are you taking a medication/drug to treat hypertension?". Treated participants were considered adequately controlled if their SBP and DBP were below 140 and $90 \mathrm{~mm} \mathrm{Hg}$, respectively.

Measured diabetes was defined as fasting plasma glucose (FPG) $\geq 7 \mathrm{mmol} / \mathrm{L}$ ( 2008) and/or the presence of oral hypoglycemic treatment and/or insulin. Reported diabetes was defined as a positive answer to the question "Have you ever been told by a doctor that you have diabetes?". Treated subjects were defined as those taking oral anti-diabetic drugs and/or insulin.

The SCORE risk function for low-risk countries of the European Society of Cardiology (Conroy et al. 2003) and recalibrated for the Swiss population (Marques-Vidal et al. 2008) was used to compute individual 10-year CVD risk. The original SCORE function was derived from a pool of 12 European prospective studies and allows the estimation of 10-year risk of fatal CVD based on gender, blood pressure, total cholesterol, and smoking status (for more information, see http://www.heartscore.org/Pages/welcome.aspx). Eligibility for hypolipidaemic treatment 
was defined as a 10 -year risk $\geq 5 \%$ or the presence of hypolipidaemic drug treatment. Reported dyslipidaemia was defined as a positive answer to the question "Have you ever been told by a doctor that you have high cholesterol?". Because no data were available for hypolipidaemic drug treatment among non-Caucasians, the analysis was restricted to Caucasian participants.

\section{Swiss Health Survey}

Data from the four Swiss Health Surveys (SHS) were obtained from the Swiss federal bureau of statistics (www.bfs.admin.ch). The SHS is a cross-sectional, nationwide, populationbased telephone survey conducted every 5 years since 1992 by the Federal Statistical Office of Switzerland under a mandate from the federal government (Calmonte et al. 2005). To date, the survey has been carried out four times, in 1992/93, 1997, 2002 and 2007. As no data for hypertension and diabetes were available in the 1992/93 survey, only data from the subsequent surveys (1997, 2002 and 2007) were used.

The study population was chosen by stratified random sampling of a database of all private Swiss households with fixed-line telephones (as opposed to mobile phones). The first sampling stratum consisted of the seven main regions: West "Leman", West-Central "Mittelland", Northwest, Zurich, North-Eastern, Central and South. The second stratum consisted of the cantons, and the number of households drawn was proportional to the population of the canton. In some cantons, oversampling of households was performed to obtain accurate cantonal estimates. The third stratum consisted of the household. One member of the household was randomly selected in advance within all members aged 15 years and over. A letter inviting this selected household member to participate in the survey was sent to each sampled subject, who was contacted thereafter by phone and interviewed using computerassisted telephone interview (CATI) software to manage dialling and data collection. Face-toface interviews were organised for subjects older than 75 years. In the case of long-term absence of a sampled subject, a proxy interviewee was requested to provide answers on behalf of the pre-defined sampled person (approximately $3 \%$ of households). The interviews were carried out in German, French or Italian, as appropriate. People who did not speak any of these three languages were excluded from the survey. Other criteria for exclusion were asylum seeker status, households without a fixed-line telephone, very poor health status and living in a nursing home (IHA-GfK 2003). The participation rate was $85 \%$ in $1997,64 \%$ in 2002 , and $66 \%$ in 2007 . It is estimated that $<2 \%$ of households were excluded owing to these exclusion criteria. Details are available http://www.bfs.admin.ch/bfs/portal/fr/index/infothek/erhebungen_quellen/blank/blank/ess/ 01.html.

The prevalence of hypertension, hypercholesterolaemia or diabetes was considered if the participants provided a positive answer to the questions: "Did a doctor or a health professional tell you that you have high blood pressure/a high cholesterol level/diabetes?", respectively. Subjects were considered as being treated for hypertension, hypercholesterolaemia or diabetes if they answered positively to the questions "Are you being treated for blood pressure/to decrease your cholesterol levels/for diabetes?", respectively. 


\section{Other data}

The following nationalities were considered: Swiss, former Yugoslavians (Serbian, Croatian, Bosnian and Herzegovinan, Kosovan and Macedonian), French, German, Italian, Portuguese and Spanish. Because of the small number of subjects, other nationalities were grouped into either "other Europeans" or "the rest of the world" (Bischoff and Wanner 2008); Turkish immigrants were not categorized because of the small sample sizes. For the CoLaus study, country of birth was considered the nationality, whereas for the SHS, nationality was asked to participants. The length of residence in Switzerland was assessed in the CoLaus study, but the SHS collected such information only for 2007.

In the CoLaus study, body weight and height were measured with participants standing without shoes in light indoor clothes. In the SHSs, the subjects were asked about their current body weight and height. Body mass index (BMI) was calculated as weight divided by height ${ }^{2}$. Subjects were considered to be normal weight, overweight, or obese if the BMI was $<25, \geq 25$ and $<30$, and $\geq 30 \mathrm{~kg} / \mathrm{m}^{2}$, respectively.

Three age categories were considered: 18 to 44,45 to 64 , and $\geq 65$ years. Education was categorised as follows: 1) no education completed + primary school (referred to as "basic"), 2) apprenticeship + secondary level (referred to as "secondary") and 3) tertiary level, which included university and other forms of education after the secondary level (referred to as "university"). Leisure-time physical activity was considered when the participant reported exercising at least once per week; no answer was considered a negative answer. Smoking status was divided into current, former (irrespective of the time since cessation) and never.

\section{Statistical analysis}

Statistical analysis was conducted using SAS v.9.2 (SAS Inc., Cary, NC, USA). Quantitative variables were expressed as mean \pm standard deviation and qualitative variables as number of participants and (percentage). Bivariate comparisons were performed using Student t-test or a chi-square test for quantitative and qualitative variables, respectively.

The impact of nationality on the risk of presenting CVRFs was assessed by multivariate logistic regression analysis adjusting for gender, age, educational level, BMI group and leisuretime physical activity. For the Swiss Health Survey, a further adjustment on survey year was applied. The effect of the length of residence was also tested using categorical variables (1-9, $10-19,20-29$ and $30+$ years) and restricting the analyses to immigrant groups. The results were expressed as odds ratio and $95 \%$ confidence intervals. Statistically significant differences were considered when $\mathrm{p}<0.05$.

\section{Results}

\section{Sample characteristics}

From the initial 6,743 participants of the CoLaus study, 6,710 (91.5\% 6,171 from the main study + 539 non-Caucasians) had complete biological data and were included in the analyses. Similarly, from the initial 49,261 participants in the SHS, 49,245 (99.9\%) had complete data for gender, age and nationality and were included. Their clinical characteristics according to nationality are summarised in Tables 1 (SHS) and 2 (CoLaus Study). Participants from southern Europe and the former Republic of Yugoslavia were younger, had a lower educational 
level, engaged less frequently in leisure-time physical activity and had lived in Switzerland for a shorter time. Immigrants from Italy, Portugal and Spain also presented lower obesity levels. Finally, the proportions of women were lower among German, Italian and Portuguese citizens.

\section{Current smoking}

In the SHS, participants from Germany, Italy, Portugal, Spain and the former Republic of Yugoslavia had a higher prevalence of smokers than Swiss nationals (Table 1). In the CoLaus study, participants from France, Portugal and the former Republic of Yugoslavia reported being smokers than Swiss nationals, while a lower prevalence of smoking was found for participants from Germany (Table 2).

Multivariate logistic regression analysis adjusting for gender, age, educational level, BMI group and leisure-time physical activity (and also survey year for SHS) showed that participants from Portugal (and to a lesser degree Spain and the rest of the world) were less likely to smoke, while participants from the former Republic of Yugoslavia were more likely to smoke when compared with Swiss nationals (Table 3). Finally, no consistent relationship was found between current smoking habits and the length of residence (not shown).

\section{Hypertension}

In the SHS, participants from Italy, Portugal, Spain and the former Republic of Yugoslavia reported less frequently being told they were hypertensive than Swiss nationals. Hypertensive subjects from Portugal and Spain and to a lesser degree from the former Republic of Yugoslavia, Germany and the rest of the world reported being treated less often than Swiss nationals. Finally, participants from Portugal and Italy reported a lower hypertension screening (Table 1).

In the CoLaus study, participants from France and Portugal reported less frequently being told they were hypertensive than Swiss nationals, while higher prevalences were found for participants from Germany and Italy. Hypertensive participants from France and Portugal also had lower treatment levels than Swiss nationals, whereas no differences were found regarding blood pressure control. These findings were further confirmed using blood pressure measurements; participants from France and Portugal presented a lower prevalence of hypertension and treatment, while participants from Italy had a higher prevalence and were more frequently treated than Swiss nationals (data not shown). Multivariate logistic regression analysis showed that participants from France and Spain (and to a lesser degree Portugal and the rest of the world) had lower odds of presenting with hypertension when compared with Swiss nationals. Regarding antihypertensive treatment and blood pressure control, no consistent difference was found between any of the nationalities studied (Table 4). Finally, in the SHS, French immigrants had lower odds than Swiss (OR=0.68, 95\% confidence interval [0.51-0.92]) of having had their blood pressure screened within the previous 12 months, while the opposite trend was found for immigrants from other European countries (OR=1.35, [1.02 1.78]).

In the CoLaus study, the length of residence was positively related with both SBP (Spearman correlation $=0.235, \mathrm{~N}=2626, \mathrm{p}<0.001)$ and DBP $(r=0.080, p<0.001)$, but this relationship was inverted after adjusting for age (Partial Spearman correlation $=-0.041$ and 0.048 for SBP and DBP, respectively, $p<0.05$ ). No significant effect of the length of residence was found on hypertension prevalence or treatment by multivariate logistic regression. However, an 
increase in the likelihood of being treated was found for subjects living in Switzerland longer than 30 years in the SHS (OR=3.55 [1.65-7.64]) but not in the Colaus study (OR=0.84 [0.371.91]).

\section{Dyslipidaemia}

In the SHS, participants from France, southern Europe, the former Republic of Yugoslavia and the rest of the world reported less frequently being told they were dyslipidaemic than Swiss nationals. Participants from Italy and Portugal also reported a lower screening for dyslipidaemia (Table 1).

In the CoLaus study (restricted to Caucasian participants), participants from France, Germany, the former Republic of Yugoslavia, other European countries and the rest of the world reported less frequently being told they were dyslipidaemic than Swiss nationals, while participants from Italy reported more frequently being dyslipidaemic. After lipid measurement and cardiovascular risk assessment, participants from France, Germany, Portugal, Spain, the former Republic of Yugoslavia, other European countries and the rest of the world were less eligible and participants from Italy being more eligible for statin treatment than Swiss nationals (not shown). Conversely, multivariate logistic regression showed no consistent differences between nationalities regarding the prevalence or treatment of dyslipidaemia (Table 5). Finally, in the SHS, no differences were found between immigrant groups and Swiss nationals regarding high cholesterol screening (not shown).

In the CoLaus study, the length of residence was positively correlated with total cholesterol (Spearman correlation $=0.158, \mathrm{~N}=2626, \mathrm{p}<0.001)$, LDL-cholesterol $(r=0.121$, $p<0.001)$ and triglyceride levels $(r=0.121, p<0.001)$, but this relationship was abolished after adjusting for age (Partial Spearman correlation $=0.019,0.004$ and 0.034 for total cholesterol, LDL cholesterol and triglycerides, respectively, $p>0.05$ ). No relationship was found between the length of residence and the prevalence of dyslipidaemia, while an increase in the likelihood of being treated was found for subjects living in Switzerland longer than 30 years in the SHS $(O R=4.24$ [1.58-11.3]) but not in the Colaus study (OR=1.20 [0.51-2.85]).

\section{Diabetes}

In the SHS, participants from France, Spain, the former Republic of Yugoslavia and the rest of the world reported less frequently being told they were diabetic than Swiss nationals. Participants from Italy, Portugal and Spain also reported a lower diabetic screening (Table 1).

In the CoLaus study, participants from France, Portugal, other European countries and the rest of the world reported less frequently being told they were diabetic than Swiss nationals, while the opposite was found for participants from Italy and the former Republic of Yugoslavia. Glucose measurements showed a lower prevalence of diabetes among participants from France, Portugal and the rest of the world, and a higher prevalence among participants from Italy and the former Republic of Yugoslavia (Table 2). Multivariate logistic regression showed no consistent differences between nationalities regarding the prevalence or treatment of diabetes (Table 6). Finally, in the SHS, no differences were found between immigrants and Swiss nationals regarding diabetes screening (data not shown). 


\section{Discussion}

To our knowledge, this is the most comprehensive study assessing the prevalence of CVRFs according to nationality among immigrants living in Switzerland. Overall, our data suggest that CVRFs are unevenly distributed among immigrants in Switzerland but that these differences are due mainly to disparities in age, leisure-time physical activity, overweight/obesity and socioeconomic status. Indeed, the Swiss healthcare system has universal health-insurance coverage. Though self-paid insurance fees are high in Switzerland relative to other countries, the existing regressive taxation and premium subsidies as well as cost-sharing exemptions ensure that vulnerable groups have good access to healthcare (OECD 2006) .

\section{Smoking}

Contrary to previous findings (Gabadinho et al. 2007) but in agreement with others (Koya and Egede 2007), a higher prevalence of smoking was found among immigrants from the former Republic of Yugoslavia. Conversely, no relationship was found between the length of residence and smoking prevalence. It is possible that the comprehensive tobacco prevention program launched by the Swiss Federal Office of Public Health (Office Fédéral de la Santé Publique 2008) has been effective, as recent data indicate a slight decrease in the prevalence of smoking in the Swiss population (Marques-Vidal et al. 2010). Another explanation is that older immigrants did not smoke before moving to Switzerland, and they did not change their behaviours after moving.

\section{Hypertension}

Immigrants from France and Southern Europe (Spain + Portugal) had lower levels of hypertension than Swiss nationals, even after adjusting for confounding factors. In agreement with a study conducted in the Netherlands (Agyemang et al. 2005), no consistent differences were found regarding high blood pressure treatment between immigrant groups relative to Swiss nationals. Some studies have also suggested that hypertension control is lower among immigrants (Agyemang et al. 2005; Verma et al. 2010), but no such differences were found, again suggesting that immigrants have the same access to health care as the Swiss population. The higher likelihood of being treated among immigrants living in Switzerland longer than 30 years (SHS data) is in agreement with other studies (Dias et al. 2008) and might be due to a better knowledge of the health system by older immigrants. Still, no such relationship was found in the CoLaus study, and further studies are needed to better assess this issue.

\section{Dyslipidaemia}

Immigrants tended to present lower levels of dyslipidaemia than Swiss nationals, but this difference was suppressed after multivariate adjustment. These findings are in agreement with the literature (Baron-Epel and Kaplan 2009; Bos et al. 2004), suggesting that most differences in CVD risk are due to socioeconomic variables and not to immigrant status. Still, this last statement has been challenged (Ujcic-Voortman et al. 2009), and some differences might be due to differing genetic backgrounds.

A longer length of residence has also been shown to be associated with an increased prevalence of dyslipidaemia (Koya and Egede 2007). In this study, no such relationship was found, while an increase in the likelihood of being treated was found for subjects living in 
Switzerland longer than 30 years (SHS data). As for hypertension, these findings suggest that immigrants benefit from the same access to health care as Swiss nationals.

\section{Diabetes}

Many studies indicate that Westernisation leads to increased levels of diabetes (Gentilucci et al. 2008; Misra and Ganda 2007; Cappuccio et al. 1997), although this statement has been challenged (Pollard et al. 2008). It has been suggested that the difference in the prevalence of diabetes between immigrants and nationals could be due partly to ethnicity (Whitty et al. 1999). Still, in this study, no differences in the prevalence of diabetes were found between immigrant groups and Swiss nationals after adjusting for major confounders. Hence, as reported above, BMI and socioeconomic factors might be more important than immigration status in terms of the prevalence of diabetes.

There is some evidence supporting the claim that diabetic immigrants tend to be treated more often than local nationals (Tran et al. 2010; Verma et al. 2010). In this study however, no such relationship was found, but the number of subjects was very small, precluding a precise assessment. Still, no differences were found for diabetes screening, suggesting that immigrants might benefit from the same access to health care as Swiss nationals.

\section{Limitations}

This study has several limitations worth noting. The participation rate in the CoLaus study was low (41\%), which might limit the generalisation of the findings; however, this participation rate is similar to other epidemiological studies (Grøtvedt et al. 2008). Secondly, it has been shown that SCORE performs differently according to ethnicity (Kumar et al. 2009). Although risk calculators that take ethnicity into account have been developed (Brindle et al. 2006), it was not possible to precisely assess the ethnicity of all the CoLaus and SHS participants. Hence, in agreement with current ESC guidelines (Graham et al. 2007), it was decided to use a single, country-calibrated equation (Marques-Vidal et al. 2008). Further, the SHS only assessed subjects with fixed telephone lines, leading to a possible selection bias as no data could be obtained from subjects who only possess mobile phones. To our knowledge, there are no data in Switzerland which might enable to assess the characteristics of the subjects who tend to prefer mobile to fixed phones, so correction is difficult. Still, according to the Federal Office of Statistics, Switzerland has one of the highest fixed lines rates among industrialized countries ${ }^{1}$, so this bias might be less important than for other countries. Height and weight were self-reported in the SHS, leading to an underestimation of obesity prevalence. This might partly explain the lower odds ratios for obesity observed in the SHS, as some obese subjects were misclassified as overweight and some overweight subjects were misclassified as normal weight, thus decreasing the association between BMI categories and CVD risk factors. The major strength of our study is that we used two population-based samples representative of the Swiss population, and that the results obtained were quite similar.

A possible explanation for the lower prevalence of some CVRFs among immigrants might be due to maintenance of their original dietary practices, as it has been showed that a Mediterranean diet is protective towards CVD (Sofi et al. 2010). Still, recent data (Bach-Faig et

\footnotetext{
${ }^{1}$ http://www.bfs.admin.ch/bfs/portal/fr/index/themen/16/04/key/approche globale.Document.25543.xls
} 
al. 2011; Baldini et al. 2009; Chen and Marques-Vidal 2007) suggest that this dietary pattern is being progressively abandoned, and it would be of interest to assess dietary intake among immigrants and Swiss nationals.

In summary, our results indicate that most CVRFs are unevenly distributed among immigrants in Switzerland but that these differences are due mainly to disparities in age, leisure-time physical activity, BMI and socioeconomic status. Management of CVRFs does not seem to differ between immigrant groups and Swiss nationals, suggesting that these groups have equal access to health care.

\section{References}

Anonymous (2008) Diagnosis and classification of diabetes mellitus. Diabetes Care 31 Suppl 1: S55-S60. doi: 10.2337/dc08-S055.

Agyemang C, Bindraban N, Mairuhu G, Montfrans G, Koopmans R, Stronks K (2005) Prevalence, awareness, treatment, and control of hypertension among Black Surinamese, South Asian Surinamese and White Dutch in Amsterdam, The Netherlands: the SUNSET study. J Hypertens 23: 1971-1977.

Bach-Faig A, Fuentes-Bol C, Ramos D, Carrasco JL, Roman B, Bertomeu IF, Cristià E, Geleva D, Serra-Majem L (2011) The Mediterranean diet in Spain: adherence trends during the past two decades using the Mediterranean Adequacy Index. Public Health Nutr 14: 622628. doi: 10.1017/S1368980010002752.

Bainey KR, Jugdutt BI (2009) Increased burden of coronary artery disease in South-Asians living in North America. Need for an aggressive management algorithm. Atherosclerosis 204: 1-10. doi: 10.1016/j.atherosclerosis.2008.09.023.

Baldini M, Pasqui F, Bordoni A, Maranesi M (2009) Is the Mediterranean lifestyle still a reality? Evaluation of food consumption and energy expenditure in Italian and Spanish university students. Public Health Nutr 12: 148-155. doi: 10.1017/S1368980008002759.

Baron-Epel O, Kaplan G (2009) Can subjective and objective socioeconomic status explain minority health disparities in Israel? Soc Sci Med 69: 1460-1467. doi: 10.1016/j.socscimed.2009.08.028.

Bischoff A, Wanner P (2008) The self-reported health of immigrant groups in Switzerland. J Immigr Minor Health 10: 325-335. doi: 10.1007/s10903-007-9089-z.

Bos V, Kunst AE, Keij-Deerenberg IM, Garssen J, Mackenbach JP (2004) Ethnic inequalities in age- and cause-specific mortality in The Netherlands. Int J Epidemiol 33: 1112-1119. doi: 10.1093/ije/dyh189.

Brindle P, May M, Gill P, Cappuccio F, D'Agostino R, Sr., Fischbacher C, Ebrahim S (2006) Primary prevention of cardiovascular disease: a web-based risk score for seven British black and minority ethnic groups. Heart 92: 1595-1602. doi: 10.1136/hrt.2006.092346.

Calmonte R, Galati-Petrecca M, Lieberherr R, Neuhaus M, Kahlmeier S (2005) Gesundheit und Gesundheitsverhalten in der Schweiz 1992-2002. Schweizerische Gesundheitsbefragung.

Cappuccio FP, Cook DG, Atkinson RW, Strazzullo P (1997) Prevalence, detection, and management of cardiovascular risk factors in different ethnic groups in south London. Heart 78: 555-563.

Carrasco-Garrido P, de Miguel AG, Barrera VH, Jiménez-Garcia R (2007) Health profiles, lifestyles and use of health resources by the immigrant population resident in Spain. Eur J Public Health 17: 503-507. doi: 10.1093/eurpub/ckl279. 
Chen Q, Marques-Vidal P (2007) Trends in food availability in Portugal in 1966-2003: comparison with other Mediterranean countries. Eur J Nutr 46: 418-427. doi: 10.1007/s00394-0070681-8.

Conroy RM, Pyörälä K, Fitzgerald AP, Sans S, Menotti A, De Backer G, De Bacquer D, Ducimetière P, Jousilahti P, Keil U, Njolstad I, Oganov RG, Thomsen T, Tunstall-Pedoe H, Tverdal A, Wedel H, Whincup P, Wilhelmsen L, Graham IM (2003) Estimation of ten-year risk of fatal cardiovascular disease in Europe: the SCORE project. Eur Heart J 24: 987-1003.

Dias SF, Severo M, Barros H (2008) Determinants of health care utilization by immigrants in Portugal. BMC Health Serv Res 8: 207. doi: 10.1186/1472-6963-8-207.

Firmann M, Mayor V, Marques-Vidal.P., Bochud M, Pécoud A, Hayoz D, Paccaud F, Preisig M, Song KS, Yuan X, Danoff TM, Stirnadel HA, Waterworth DM, Mooser V, Waeber G, Vollenweider $P$ (2008) The CoLaus study: a population-based study to investigate the epidemiology and genetic determinants of cardiovascular risk factors and metabolic syndrome. BMC Cardiovasc Disord 8: 6.

Gabadinho A, Wanner P, Dahinden J (2007) La santé des populations migrantes en Suisse: une analyse des données du GMM [Health of migrants in Switzerland: analysis of the GMM data]. 49: 1-90.

Gadd M, Johansson SE, Sundquist J, Wandell P (2003) Morbidity in cardiovascular diseases in immigrants in Sweden. J Intern Med 254: 236-243.

Gentilucci UV, Picardi A, Manfrini S, Khazrai YM, Fioriti E, Altomare M, Guglielmi C, Di Stasio E, Pozzilli P (2008) Westernization of the Filipino population resident in Rome: obesity, diabetes and hypertension. Diabetes Metab Res Rev 24: 364-370. doi: 10.1002/dmrr.807.

Graham I, Atar D, Borch-Johnsen K, Boysen G, Burell G, Cifkova R, Dallongeville J, De Backer G, Ebrahim S, Gjelsvik B, Herrmann-Lingen C, Hoes A, Humphries S, Knapton M, Perk J, Priori SG, Pyörälä K, Reiner Z, Ruilope L, Sans-Menendez S, Op Reimer WS, Weissberg P, Wood D, Yarnell J, Zamorano JL, Walma E, Fitzgerald T, Cooney MT, Dudina A, Vahanian A, Camm J, De Caterina R, Dean V, Dickstein K, Funck-Brentano C, Filippatos G, Hellemans I, Kristensen SD, McGregor K, Sechtem U, Silber S, Tendera M, Widimsky P, Zamorano JL, Altiner A, Bonora E, Durrington PN, Fagard R, Giampaoli S, Hemingway H, Hakansson J, Kjeldsen SE, Larsen ML, Mancia G, Manolis AJ, Orth-Gomer K, Pedersen T, Rayner M, Ryden L, Sammut M, Schneiderman N, Stalenhoef AF, Tokgozoglu L, Wiklund O, Zampelas A (2007) European guidelines on cardiovascular disease prevention in clinical practice: executive summary. Fourth Joint Task Force of the European Society of Cardiology and other societies on cardiovascular disease prevention in clinical practice (constituted by representatives of nine societies and by invited experts). Eur J Cardiovasc Prev Rehabil 14 Suppl 2: E1-40. doi: 10.1097/01.hjr.0000277984.31558.c4.

Grøtvedt L, Kuulasmaa K, Tolonen H, Heldal J, Graff-Iversen S (2008) Sampling and recruitment. In: Tolonen H, Koponen P, Aromaa A, Conti S, Graff-Iversen S et al., editors. Review of health examination surveys in Europe. Helsinki, Finland: KTL - National Public Health Institute. pp. 82-126.

IHA-GfK (2003) Schweizerische Gesundheitsbefragung SGB 2002 - Schlussbericht zur Datenerhebung.

Kouris-Blazos A (2002) Morbidity mortality paradox of 1st generation Greek Australians. Asia Pac J Clin Nutr 11 Suppl 3: S569-S575.

Koya DL, Egede LE (2007) Association between length of residence and cardiovascular disease risk factors among an ethnically diverse group of United States immigrants. J Gen Intern Med 22: 841-846. doi: 10.1007/s11606-007-0163-y. 
Kumar BN, Selmer R, Lindman AS, Tverdal A, Falster K, Meyer HE (2009) Ethnic differences in SCORE cardiovascular risk in Oslo, Norway. Eur J Cardiovasc Prev Rehabil 16: 229-234. doi: 10.1097/HJR.0b013e3283294b07.

Marques-Vidal P, Cerveira J, Paccaud F, Cornuz J (2010) Smoking trends in Switzerland, 19922007: a time for optimism? J Epidemiol Community Health 65: 281-286. doi: 10.1136/jech.2009.099424.

Marques-Vidal P, Rodondi N, Bochud M, Pécoud A, Hayoz D, Paccaud F, Mooser V, Waeber G, Vollenweider $P$ (2008) Predictive accuracy and usefulness of calibration of the ESC SCORE in Switzerland. Eur J Cardiovasc Prev Rehabil 15: 402-408. doi: 10.1097/HJR.0b013e3282fb040f.

Misra A, Ganda OP (2007) Migration and its impact on adiposity and type 2 diabetes. Nutrition 23: 696-708. doi: 10.1016/j.nut.2007.06.008.

OECD (19-10-2006) OECD Reviews of Health Systems - Switzerland. Paris, France: Organisation of Economic Co-operation and Development. 190 p.

Office Fédéral de la Santé Publique (2008) Dossier sur la politique en matière de tabagisme dans

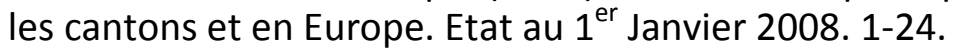

Office Fédéral des Migrations (ODM) (2010) Rapport sur la migration 2009. 1-50.

Pollard TM, Unwin N, Fischbacher C, Chamley JK (2008) Differences in body composition and cardiovascular and type 2 diabetes risk factors between migrant and British-born British Pakistani women. Am J Hum Biol 20: 545-549. doi: 10.1002/ajhb.20773.

Sofi F, Abbate R, Gensini GF, Casini A (2010) Accruing evidence on benefits of adherence to the Mediterranean diet on health: an updated systematic review and meta-analysis. Am J Clin Nutr 92: 1189-1196. doi: 10.3945/ajcn.2010.29673.

Tran AT, Diep LM, Cooper JG, Claudi T, Straand J, Birkeland K, Ingskog W, Jenum AK (2010) Quality of care for patients with type 2 diabetes in general practice according to patients' ethnic background: a cross-sectional study from Oslo, Norway. BMC Health Serv Res 10: 145. doi: 10.1186/1472-6963-10-145.

Ujcic-Voortman JK, Schram MT, Jacobs-van der Bruggen MA, Verhoeff AP, Baan CA (2009) Diabetes prevalence and risk factors among ethnic minorities. Eur J Public Health 19: 511-515. doi: 10.1093/eurpub/ckp096.

Verma A, Birger R, Bhatt H, Murray J, Millett C, Saxena S, Banarsee R, Gnani S, Majeed A (2010) Ethnic disparities in diabetes management: a 10-year population-based repeated crosssectional study in UK primary care. J Public Health (Oxf) 32: 250-258. doi: 10.1093/pubmed/fdp114.

Wanner P, Bouchardy C, Raymond L (2000) Mortalité des étrangers en Suisse : analyse par grand groupe de causes et par type de cancer, 1989-1992.

Whitty CJ, Brunner EJ, Shipley MJ, Hemingway H, Marmot MG (1999) Differences in biological risk factors for cardiovascular disease between three ethnic groups in the Whitehall II study. Atherosclerosis 142: 279-286. 


\section{Tables}

Table 1: participants' characteristics between immigrant groups and Swiss nationals, Swiss Health Surveys 1997,2002 and 2007.

\begin{tabular}{|c|c|c|c|c|c|c|c|c|c|c|}
\hline & Swiss & German & Italian & French & Spanish & Portuguese & $\begin{array}{c}\text { Former } \\
\text { Yugoslavia } \\
*\end{array}$ & $\begin{array}{c}\text { Other } \\
\text { Europe } * *\end{array}$ & $\begin{array}{l}\text { Other } \\
\text { World }\end{array}$ & Test \\
\hline Sample size & 42692 & 884 & 1875 & 475 & 429 & 560 & 549 & 1137 & 644 & \\
\hline Age (years) & $50.1 \pm 17.7$ & $47.8 \pm 15.7$ & $47.2 \pm 16.2$ & $45.8 \pm 15.2$ & $40.9 \pm 13.5$ & $36.2 \pm 9.5$ & $37.8 \pm 10.9$ & $43.5 \pm 15.8$ & $37.6 \pm 11.4$ & 153.9 \\
\hline Residency time $(y r s)^{a}$ & - & $14.9 \pm 15.5$ & $35.3 \pm 15.2$ & $16.6 \pm 14.7$ & $27.7 \pm 11.8$ & $17.0 \pm 7.6$ & $18.0 \pm 8.1$ & $19.3 \pm 14.9$ & $11.0 \pm 9.0$ & 88.49 \\
\hline Women (\%) & $23797(55.7)$ & $452(51.1)$ & $865(46.1)$ & $253(53.3)$ & $208(48.5)$ & $300(53.6)$ & $273(49.7)$ & $613(53.9)$ & $375(58.2)$ & 90.03 \\
\hline \multicolumn{11}{|l|}{ Educational level (\%) } \\
\hline Basic & $6731(15.8)$ & $49(5.5)$ & $808(43.1)$ & $58(12.2)$ & $187(43.6)$ & $381(68.0)$ & $193(35.2)$ & $259(22.8)$ & $182(28.3)$ & \\
\hline Secondary & $27100(63.5)$ & $444(50.2)$ & $913(48.7)$ & $240(50.5)$ & $200(46.6)$ & $170(30.4)$ & $306(55.7)$ & $520(45.7)$ & $281(43.6)$ & 2910 \\
\hline University & $8861(20.8)$ & $391(44.2)$ & $154(8.2)$ & $177(37.3)$ & $42(9.8)$ & $9(1.6)$ & $50(9.1)$ & $358(31.5)$ & $181(28.1)$ & \\
\hline \multicolumn{11}{|l|}{ Smoking status (\%) } \\
\hline Never & $20705(48.5)$ & $400(45.3)$ & $842(44.9)$ & 180 (37.9) & $178(41.5)$ & $254(45.4)$ & $206(37.5)$ & $524(46.1)$ & 384 (59.6) & \\
\hline Former & 9324 (21.9) & $214(24.2)$ & 395 (21.1) & $123(25.9)$ & $86(20.1)$ & 109 (19.5) & $88(16.0)$ & $237(20.8)$ & $93(14.4)$ & 175.1 \\
\hline Current & $12646(29.6)$ & $270(30.5)$ & $637(34.0)$ & $172(36.2)$ & $165(38.5)$ & $197(35.2)$ & $255(46.5)$ & $376(33.1)$ & 167 (25.9) & \\
\hline Leisure-time PA (\%) ${ }^{b}$ & $25787(62.5)$ & $618(71.3)$ & $793(44.7)$ & $239(51.5)$ & $183(46.3)$ & $211(40.6)$ & $225(51.4)$ & $573(58.7)$ & $276(53.3)$ & 452.0 \\
\hline BMI $\left(k g / m^{2}\right)$ & $24.3 \pm 4.1$ & $23.9 \pm 3.7$ & $25.3 \pm 4.2$ & $23.7 \pm 3.9$ & $24.8 \pm 3.9$ & $24.5 \pm 3.7$ & $25.2 \pm 3.9$ & $24.3 \pm 4.1$ & $23.6 \pm 4.2$ & 23.47 \\
\hline \multicolumn{11}{|l|}{ BMI class $(\%)^{\mathrm{c}}$} \\
\hline Normal & $26634(62.4)$ & $608(68.8)$ & 955 (50.9) & $329(69.3)$ & $238(55.5)$ & 334 (59.6) & 285 (51.9) & 704 (61.9) & 447 (69.4) & \\
\hline Overweight & $12565(29.4)$ & $227(25.7)$ & 705 (37.6) & $115(24.2)$ & 159 (37.1) & $191(34.1)$ & $200(36.4)$ & 339 (29.8) & 159 (24.7) & 190.0 \\
\hline Obese & $3493(8.2)$ & $49(5.5)$ & 215 (11.5) & $31(6.5)$ & $32(7.5)$ & $35(6.3)$ & $64(11.7)$ & $94(8.3)$ & $38(5.9)$ & \\
\hline
\end{tabular}




\begin{tabular}{|c|c|c|c|c|c|c|c|c|c|c|}
\hline Hypertension (\%) ${ }^{d}$ & $10901(25.5)$ & 176 (19.9) & $465(24.8)$ & $74(15.6)$ & 68 (15.9) & $82(14.6)$ & 95 (17.3) & $230(20.2)$ & $84(13.0)$ & 172.0 \\
\hline Treatment (\%) $^{\mathrm{e}}$ & $6430(59.0)$ & $102(58.0)$ & $216(46.5)$ & $45(60.8)$ & $23(33.8)$ & $28(34.2)$ & $42(44.2)$ & $124(53.9)$ & $38(45.2)$ & 80.0 \\
\hline Screening (\%) ${ }^{f}$ & $32752(91.8)$ & 676 (91.9) & $1365(90.4)$ & $361(87.2)$ & $288(87.8)$ & $428(90.1)$ & $350(91.6)$ & $831(93.6)$ & 464 (91.9) & 26.65 \\
\hline \multicolumn{11}{|l|}{ Lipids } \\
\hline Dyslipidaemia (\%) ${ }^{\mathrm{g}}$ & 7131 (16.7) & $163(18.4)$ & 299 (16.0) & $84(17.7)$ & 51 (11.9) & $73(13.0)$ & $39(7.1)$ & $154(13.5)$ & 51 (7.9) & 92.69 \\
\hline 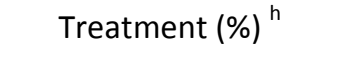 & 2471 (34.7) & $33(20.3)$ & 105 (35.1) & $25(29.8)$ & $9(17.7)$ & $15(20.6)$ & $10(25.6)$ & $45(29.2)$ & $14(27.5)$ & 31.66 \\
\hline Screening (\%) ${ }^{i}$ & $34062(90.8)$ & 713 (90.9) & $1414(88.4)$ & $375(86.8)$ & $324(89.3)$ & $420(87.9)$ & $396(91.2)$ & $919(92.5)$ & $501(91.8)$ & 28.89 \\
\hline \multicolumn{11}{|l|}{ Glucose/diabetes } \\
\hline Diabetes (\%) ${ }^{\mathrm{j}}$ & $1932(4.5)$ & $26(2.9)$ & $93(5.0)$ & $14(3.0)$ & $20(4.7)$ & $14(2.5)$ & $13(2.4)$ & $35(3.1)$ & $17(2.6)$ & 29.62 \\
\hline Screening (\%) ${ }^{k}$ & $34191(91.3)$ & $724(92.1)$ & 1418 (89.5) & $375(88.0)$ & $313(87.9)$ & $413(87.9)$ & $398(92.1)$ & $915(92.4)$ & $508(90.6)$ & 26.43 \\
\hline
\end{tabular}

Results are expressed as the number of subjects and (percentage) or as the average \pm standard deviation. BMI, body mass index; PA; physical activity. Statistical analysis by chi-square or analysis of variance: all comparisons are significant at $p<0.001$.

* Serbian, Croatian, Bosnian and Herzegovinan, Kosovan and Macedonian.

** Because of the small number of subjects, other nationalities were grouped into either "Other, Europe" or "Other, world".

${ }^{\text {a }}$ For the year 2007 only.

${ }^{\mathrm{b}}$ Considered when the participant reported exercising at least once per week.

c Participants were considered to be normal weight, overweight, or obese if their body mass index was $<25, \geq 25$ and $<30$, and $\geq 30$ $\mathrm{kg} / \mathrm{m}^{2}$, respectively.

'Defined as a positive answer to the question "Did a doctor or a health professional tell you that you have high blood pressure?".

e Defined as a positive answer to the question "Are you being treated for blood pressure?".

f Defined as the answer "within the last 12 months" to the question "when was your blood pressure measured for the last time?".

"Defined as a positive answer to the question: "Did a doctor or a health professional tell you that you have a high cholesterol?".

h Defined as a positive answer to the question "Are you being treated decrease your cholesterol levels?".

'Defined as the answer "within the last 12 months" to the question "when was your cholesterol measured for the last time?". 
' Defined as a positive answer to the question: "Did a doctor or a health professional tell you that you have diabetes?".

"Defined as the answer "within the last 12 months" to the question "when was your blood sugar measured for the last time?". 
Table 2: participant's characteristics between immigrant groups and Swiss nationals, Cohorte Lausannoise (CoLaus) study $2003-2006$.

\begin{tabular}{|c|c|c|c|c|c|c|c|c|c|c|}
\hline & Swiss & German & Italian & French & Spanish & Portuguese & $\begin{array}{c}\text { Former } \\
\text { Yugoslavia } \\
*\end{array}$ & $\begin{array}{c}\text { Other } \\
\text { Europe ** }\end{array}$ & $\begin{array}{l}\text { Other } \\
\text { World }\end{array}$ & Test \\
\hline Sample size & 4036 & 92 & 404 & 436 & 262 & 390 & 87 & 529 & 474 & \\
\hline Age (years) & $54.0 \pm 10.9$ & $55.6 \pm 11.1$ & $56.2 \pm 10.6$ & $51.8 \pm 10.6$ & $51.0 \pm 8.7$ & $44.5 \pm 6.2$ & $45.9 \pm 7.3$ & $50.9 \pm 10.1$ & $48.1 \pm 8.9$ & $65.41 * * *$ \\
\hline Residency time (years) & - & $33.1 \pm 12.2$ & $36.9 \pm 11.7$ & $26.9 \pm 15.6$ & $29.4 \pm 10.6$ & $19.0 \pm 7.4$ & $19.4 \pm 9.8$ & $24.0 \pm 13.5$ & $21.1 \pm 12.3$ & $86.03 * * *$ \\
\hline Women (\%) & $2151(53.3)$ & $69(75.0)$ & $165(40.8)$ & $238(54.6)$ & $128(48.9)$ & $176(45.1)$ & $39(44.8)$ & $300(56.7)$ & $262(55.3)$ & $59.65 * * *$ \\
\hline Basic & $526(13.0)$ & $9(9.8)$ & $183(45.3)$ & $52(11.9)$ & $135(51.5)$ & 302 (77.4) & $34(39.1)$ & $80(15.1)$ & $84(17.7)$ & \\
\hline Secondary & $2771(68.7)$ & $58(63.0)$ & $188(46.5)$ & $263(60.3)$ & $108(41.2)$ & $80(20.5)$ & $44(50.6)$ & $241(45.6)$ & $238(50.2)$ & $1478^{* * *}$ \\
\hline University & 739 (18.3) & $25(27.2)$ & $33(8.2)$ & $121(27.8)$ & $19(7.3)$ & $8(2.1)$ & $9(10.3)$ & $208(39.3)$ & $152(32.1)$ & \\
\hline \multicolumn{11}{|l|}{ Smoking status (\%) } \\
\hline \multicolumn{11}{|l|}{ BMI class $(\%)^{b}$} \\
\hline Normal & $2040(50.6)$ & $49(53.3)$ & $124(30.7)$ & $245(56.2)$ & $96(36.6)$ & $148(38.0)$ & $15(17.2)$ & $294(55.6)$ & $215(45.4)$ & \\
\hline Overweight & $1397(34.6)$ & $32(34.8)$ & $194(48.0)$ & $148(33.9)$ & $112(42.8)$ & $168(43.1)$ & $46(52.9)$ & $169(32.0)$ & $190(40.1)$ & $156.8 * * *$ \\
\hline Obese & $599(14.8)$ & $11(12.0)$ & $86(21.3)$ & $43(9.9)$ & $54(20.6)$ & $74(19.0)$ & $26(29.9)$ & $66(12.5)$ & $69(14.6)$ & \\
\hline \multicolumn{11}{|l|}{ Blood pressure } \\
\hline $\mathrm{SBP}(\mathrm{mm} \mathrm{Hg})$ & $129 \pm 18$ & $131 \pm 22$ & $132 \pm 18$ & $125 \pm 18$ & $127 \pm 16$ & $125 \pm 16$ & $129 \pm 19$ & $126 \pm 18$ & $124 \pm 17$ & $11.21 * * *$ \\
\hline $\mathrm{DBP}(\mathrm{mm} \mathrm{Hg})$ & $79 \pm 11$ & $78 \pm 13$ & $80 \pm 10$ & $78 \pm 12$ & $80 \pm 10$ & $80 \pm 10$ & $81 \pm 11$ & $79 \pm 11$ & $79 \pm 11$ & $2.25 *$ \\
\hline Hypertension (\%) ${ }^{c}$ & $1528(37.9)$ & $38(41.3)$ & $196(48.5)$ & $123(28.2)$ & $95(36.3)$ & $96(24.6)$ & $31(35.6)$ & $158(29.9)$ & $112(23.6)$ & $108.0 * * *$ \\
\hline
\end{tabular}




Treatment (\%) $^{d} \quad 743(48.6) \quad 23(60.5) \quad 115(58.7) \quad 51(41.5) \quad 50(52.6) \quad 34(35.4) \quad 19(61.3) \quad 69(43.7) \quad 49(43.8) \quad 24.52 * *$

Table 2 (continued): participant's characteristics between immigrant groups and Swiss nationals, Cohorte Lausannoise (CoLaus)

study.

\begin{tabular}{|c|c|c|c|c|c|c|c|c|c|c|}
\hline & Swiss & German & Italian & French & Spanish & Portuguese & $\begin{array}{c}\text { Former } \\
\text { Yugoslavia }\end{array}$ & $\begin{array}{l}\text { Other } \\
\text { Europe }\end{array}$ & $\begin{array}{l}\text { Other } \\
\text { World }\end{array}$ & Test \\
\hline${\text { Control }(\%)^{e}}^{e}$ & $362(48.7)$ & $6(26.1)$ & $54(47.0)$ & $23(45.1)$ & $26(52.0)$ & $12(35.3)$ & $6(31.6)$ & $39(56.5)$ & $23(46.9)$ & $11.39^{\mathrm{NS}}$ \\
\hline Hypertension (\%) ${ }^{f}$ & $1111(27.5)$ & $32(34.8)$ & $146(36.1)$ & $87(20.0)$ & $68(26.0)$ & $61(15.6)$ & $27(31.0)$ & $113(21.4)$ & 85 (17.9) & $83.59 * * *$ \\
\hline 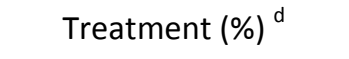 & $743(77.0)$ & $23(79.3)$ & $115(89.2)$ & $51(68.9)$ & $50(86.2)$ & $34(68.0)$ & 19 (90.5) & $69(71.1)$ & $49(76.6)$ & $22.81 * *$ \\
\hline \multicolumn{11}{|l|}{ Lipids } \\
\hline LDL-CL (mmol/L) & $3.34 \pm 0.91$ & $3.38 \pm 0.93$ & $3.37 \pm 0.88$ & $3.31 \pm 0.94$ & $3.42 \pm 0.93$ & $3.38 \pm 1.03$ & $3.26 \pm 0.89$ & $3.27 \pm 0.91$ & $3.24 \pm 0.90$ & $1.47^{\mathrm{NS}}$ \\
\hline $\mathrm{TG}(\mathrm{mmol} / \mathrm{L})$ & $1.41 \pm 1.16$ & $1.18 \pm 0.55$ & $1.46 \pm 1.01$ & $1.26 \pm 1.00$ & $1.31 \pm 0.94$ & $1.59 \pm 2.04$ & $1.82 \pm 1.33$ & $1.32 \pm 1.06$ & $1.26 \pm 0.81$ & $8.09 * * *^{\S}$ \\
\hline Dyslipidaemia (\%) ${ }^{\mathrm{e}}$ & & & & & & & & & & $121.2 * * *$ \\
\hline $\mathrm{g}$ & $942(23.5)$ & $15(16.5)$ & $131(32.5)$ & $65(15.5)$ & 44 (16.9) & $29(7.5)$ & $9(10.3)$ & $62(17.0)$ & $15(9.9)$ & \\
\hline \multicolumn{11}{|l|}{ Glucose/diabetes } \\
\hline Glucose (mmol/L) & $5.57 \pm 1.18$ & $5.52 \pm 1.11$ & $5.82 \pm 1.47$ & $5.45 \pm 1.03$ & $5.54 \pm 0.83$ & $5.50 \pm 0.88$ & $5.52 \pm 0.89$ & $5.48 \pm 1.27$ & $5.31 \pm 0.82$ & $6.30 * * *$ \\
\hline Diabetes (\%) ${ }^{\mathrm{k}}$ & 277 (6.9) & $5(5.4)$ & $49(12.1)$ & $20(4.6)$ & $17(6.5)$ & $17(4.4)$ & $9(10.3)$ & $27(5.1)$ & $14(3.0)$ & $41.40 * * *$ \\
\hline Treatment (\%) ${ }^{\prime}$ & $176(63.5)$ & $4(80.0)$ & $32(65.3)$ & $13(65.0)$ & $9(52.9)$ & $12(70.6)$ & $6(66.7)$ & $16(59.3)$ & $6(42.9)$ & $4.61^{\text {NS }}$ \\
\hline Diabetes (\%) ${ }^{\mathrm{m}}$ & $204(5.1)$ & $5(5.4)$ & $37(9.2)$ & $17(3.9)$ & $14(5.3)$ & $13(3.3)$ & $7(8.1)$ & $20(3.8)$ & $11(2.3)$ & $29.19 * * *$ \\
\hline Treatment (\%) ${ }^{\prime}$ & $176(86.3)$ & $4(80.0)$ & $32(86.5)$ & $13(76.5)$ & $9(64.3)$ & $12(92.3)$ & $6(85.7)$ & $16(80.0)$ & $6(54.6)$ & NA \\
\hline
\end{tabular}


Results are expressed as the number of subjects and (percentage) or as the average \pm standard deviation. BMI, body mass index; $\mathrm{CL}$, cholesterol; DBP, diastolic blood pressure; PA; physical activity; SBP, systolic blood pressure; TG; triglycerides.. Statistical analysis by chi-square or analysis of variance: ${ }^{\text {NS }}$, not significant; ${ }^{*}, \mathrm{p}<0.05 ;{ }^{* *}, \mathrm{p}<0.01 ;{ }^{* * *}, \mathrm{p}<0.001 ; \mathrm{NA}$, not assessable.

* Serbian, Croatian, Bosnian and Herzegovinan, Kosovan and Macedonian.

** Because of the small number of subjects, other nationalities were grouped into either "Other, Europe" or "Other, world".

$\S$ Statistical analysis performed on log-transformed data

${ }^{a}$ Considered when the participant reported exercising at least once per week

${ }^{\mathrm{b}}$ Participants were considered to be normal weight, overweight, or obese if their body mass index was $<25, \geq 25$ and $<30$, and $\geq 30$ $\mathrm{kg} / \mathrm{m}^{2}$, respectively

${ }^{c}$ Defined as SBP (mean of two measurements) $\geq 140 \mathrm{~mm} \mathrm{Hg}$ or DBP (mean of two measurements) $\geq 90 \mathrm{~mm}$ Hg or anti-hypertensive medication.

d Defined as a positive answer to the question "Are you taking a medication/drug to treat hypertension?".

e Defined as SBP (mean of two measurements) $<140 \mathrm{~mm} \mathrm{Hg}$ and DBP (mean of two measurements) $<90 \mathrm{~mm} \mathrm{Hg}$.

${ }^{f}$ Defined as a positive answer to the question "Have you ever been told by a doctor that you have high blood pressure (hypertension)?”

${ }^{g}$ Defined as a 10 -year risk $\geq 5 \%$ (as assessed by the SCORE risk function for low-risk countries of the European Society of Cardiology recalibrated for the Swiss population) or the presence of hypolipidaemic drug treatment.

${ }^{\mathrm{h}}$ Defined as the presence of a hypolipidaemic drug treatment.

'Restricted to Caucasian participants.

'Defined as a positive answer to the question "Have you ever been told by a doctor that you have high cholesterol?".

${ }^{k}$ Defined as a fasting plasma glucose $\geq 7 \mathrm{mmol} / \mathrm{L}$ and/or the presence of oral hypoglycemic treatment and/or insulin.

'Defined as participants who take oral anti-diabetic drugs and/or insulin.

m Defined as a positive answer to the question "Have you ever been told by a doctor that you have diabetes?". 
Table 3: multivariate analysis of the associations between nationality and the prevalence of smoking for the Swiss Health Surveys (SHS, 1997, 2002 and 2007) and the Cohorte Lausannoise (CoLaus) study (2003-2006), adjusting for confounding variables.

\begin{tabular}{|c|c|c|}
\hline & CoLaus & SHS \\
\hline \multicolumn{3}{|l|}{ Gender } \\
\hline Female & 1 (ref.) & 1 (ref.) \\
\hline Male & $0.71[0.63-0.80]$ & $0.59[0.57-0.62]$ \\
\hline \multicolumn{3}{|l|}{ Age groups } \\
\hline $18-44$ & 1 (ref.) & 1 (ref.) \\
\hline $45-64$ & $0.83[0.73-0.94]$ & $0.76[0.72-0.79]$ \\
\hline $65+$ & $0.49[0.41-0.59]$ & $0.27[0.25-0.29]$ \\
\hline \multicolumn{3}{|l|}{ Education } \\
\hline Basic & 1 (ref.) & 1 (ref.) \\
\hline Secondary & $0.83[0.71-0.96]$ & $0.90[0.85-0.96]$ \\
\hline University & $0.55[0.45-0.67]$ & $0.68[0.64-0.74]$ \\
\hline \multicolumn{3}{|l|}{ BMI group ${ }^{a}$} \\
\hline Normal & 1 (ref.) & 1 (ref.) \\
\hline Overweight & $0.69[0.61-0.79]$ & $0.77[0.74-0.81]$ \\
\hline Obese & $0.50[0.42-0.60]$ & $0.74[0.68-0.80]$ \\
\hline \multicolumn{3}{|l|}{ Leisure-time PA ${ }^{\mathrm{b}}$} \\
\hline No & 1 (ref.) & 1 (ref.) \\
\hline Yes & $0.62[0.55-0.70]$ & $0.71[0.68-0.74]$ \\
\hline \multicolumn{3}{|l|}{ Nationality } \\
\hline Swiss & 1 (ref.) & 1 (ref.) \\
\hline German & $0.87[0.52-1.45]$ & $1.04[0.89-1.20]$ \\
\hline Italian & $0.91[0.71-1.16]$ & $0.96[0.87-1.07]$ \\
\hline French & $1.10[0.88-1.37]$ & 1.19 [0.98-1.45] \\
\hline Spanish & $0.70[0.52-0.95]$ & $1.03[0.83-1.26]$ \\
\hline Portuguese & $0.68[0.52-0.88]$ & $0.79[0.66-0.96]$ \\
\hline \multicolumn{3}{|l|}{ Former } \\
\hline Yugoslavia $^{c}$ & $0.92[0.57-1.48]$ & $1.50[1.23-1.82]$ \\
\hline Other, Europe ${ }^{d}$ & $0.78[0.62-0.97]$ & $0.97[0.85-1.12]$ \\
\hline Other, World & $0.91[0.73-1.13]$ & $0.64[0.52-0.78]$ \\
\hline
\end{tabular}


Results are expressed as the odds ratio and [95\% confidence interval]. BMI, body mass index; PA, physical activity. Statistical analysis by multivariate logistic regression. For the SHS, a further adjustment on the survey was performed.

a Participants were considered to be normal weight, overweight, or obese if their body mass index was $<25, \geq 25$ and $<30$, and $\geq 30 \mathrm{~kg} / \mathrm{m}^{2}$, respectively.

${ }^{\mathrm{b}}$ Considered when the participant reported exercising at least once per week.

${ }^{\mathrm{c}}$ Serbian, Croatian, Bosnian and Herzegovinan, Kosovan and Macedonian.

${ }^{d}$ Because of the small number of subjects, other nationalities were grouped into either "Other, Europe" or "Other, world". 
Table 4: multivariate analysis of the associations between nationality and the prevalence and management of self-reported hypertension for the Swiss Health Surveys (SHS, 1997, 2002 and 2007) and the Cohorte Lausannoise (CoLaus) study (2003-2006), adjusting for confounding variables

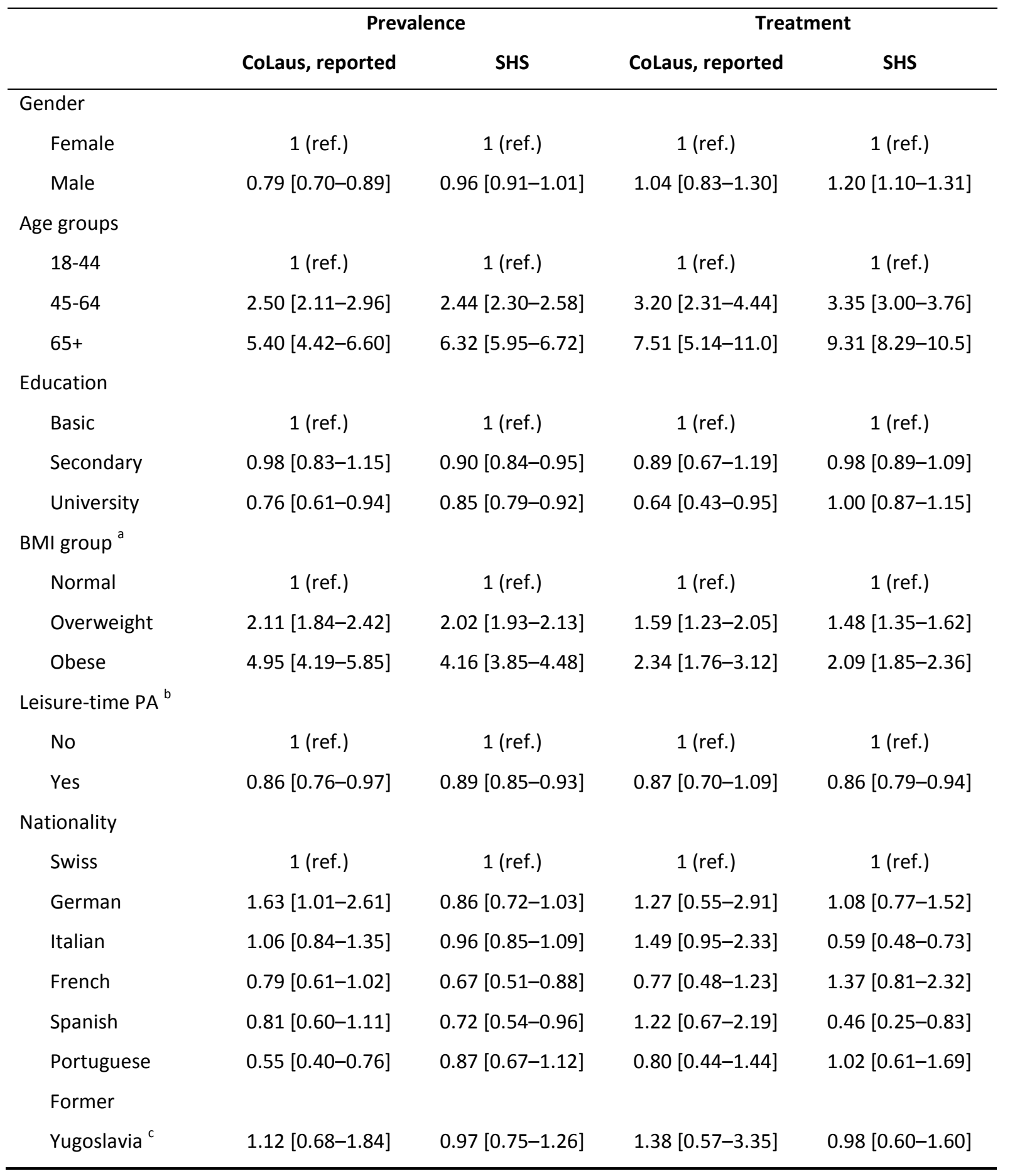




\begin{tabular}{lllll} 
Other, Europe $^{d}$ & $0.89[0.70-1.13]$ & $1.01[0.85-1.19]$ & $0.94[0.61-1.45]$ & $1.02[0.75-1.39]$ \\
Other, World & $0.68[0.53-0.89]$ & $0.93[0.72-1.19]$ & $0.89[0.55-1.45]$ & $1.39[0.85-2.25]$ \\
\hline
\end{tabular}

Self-reported hypertension was defined as a positive answer to the question "Have you ever been told by a doctor that you have high blood pressure (hypertension)?" Results are expressed as the odds ratio and [95\% confidence interval]. BMI, body mass index; PA, physical activity. Statistical analysis by multivariate logistic regression. For the SHS, a further adjustment on the survey was performed.

${ }^{\text {a }}$ Participants were considered to be normal weight, overweight, or obese if their body mass index was $<25, \geq 25$ and $<30$, and $\geq 30 \mathrm{~kg} / \mathrm{m}^{2}$, respectively.

${ }^{b}$ Considered when the participant reported exercising at least once per week.

${ }^{c}$ Serbian, Croatian, Bosnian and Herzegovinan, Kosovan and Macedonian.

${ }^{d}$ Because of the small number of subjects, other nationalities were grouped into either "Other, Europe" or "Other, world". 
Table 5: multivariate analysis of the association between nationality and the prevalence and management of self-reported dyslipidaemia for the Swiss Health Surveys (SHS, 1997, 2002 and 2007) and the Cohorte Lausannoise (CoLaus) study (2003-2006), adjusting for confounding variables.

\begin{tabular}{|c|c|c|c|c|}
\hline & \multicolumn{2}{|c|}{ Prevalence } & \multicolumn{2}{|c|}{ Treatment } \\
\hline & CoLaus, reported* & SHS & CoLaus, reported* & SHS \\
\hline \multicolumn{5}{|l|}{ Gender } \\
\hline Female & 1 (ref.) & 1 (ref.) & 1 (ref.) & 1 (ref.) \\
\hline Male & $0.7[0.62-0.8]$ & $0.78[0.74-0.83]$ & $0.70[0.56-0.88]$ & $0.73[0.65-0.81]$ \\
\hline \multicolumn{5}{|l|}{ Age groups } \\
\hline $18-44$ & 1 (ref.) & 1 (ref.) & 1 (ref.) & 1 (ref.) \\
\hline $45-64$ & $2.74[2.28-3.29]$ & 2.84 [2.66-3.03] & $3.62[2.32-5.66]$ & $2.36[2.01-2.77]$ \\
\hline $65+$ & $4.40[3.55-5.45]$ & $4.18[3.90-4.48]$ & $8.56[5.30-13.8]$ & $5.62[4.78-6.60]$ \\
\hline \multicolumn{5}{|l|}{ Education } \\
\hline Basic & 1 (ref.) & 1 (ref.) & 1 (ref.) & 1 (ref.) \\
\hline Secondary & $1.01[0.85-1.20]$ & $1.00[0.93-1.07]$ & $1.05[0.78-1.42]$ & $0.89[0.78-1.02]$ \\
\hline University & $0.70[0.55-0.88]$ & $1.13[1.04-1.23]$ & $0.79[0.52-1.22]$ & $0.84[0.70-1.00]$ \\
\hline \multicolumn{5}{|l|}{ BMI group ${ }^{a}$} \\
\hline Normal & 1 (ref.) & 1 (ref.) & 1 (ref.) & 1 (ref.) \\
\hline Overweight & 1.73 [1.50-1.99] & $1.48[1.40-1.56]$ & $1.49[1.16-1.93]$ & $1.47[1.31-1.64]$ \\
\hline Obese & $2.45[2.06-2.91]$ & $1.60[1.47-1.75]$ & 2.15 [1.59-2.89] & 1.95 [1.66-2.29] \\
\hline \multicolumn{5}{|l|}{ Leisure-time PA ${ }^{\mathrm{b}}$} \\
\hline No & 1 (ref.) & 1 (ref.) & 1 (ref.) & 1 (ref.) \\
\hline Yes & $0.92[0.81-1.04]$ & $0.88[0.84-0.93]$ & $0.73[0.58-0.92]$ & $0.79[0.71-0.88]$ \\
\hline \multicolumn{5}{|l|}{ Nationality } \\
\hline Swiss & 1 (ref.) & 1 (ref.) & 1 (ref.) & 1 (ref.) \\
\hline German & 0.84 [0.49-1.44] & $1.22[1.02-1.46]$ & $0.64[0.23-1.80]$ & $0.54[0.36-0.82]$ \\
\hline Italian & $0.88[0.69-1.13]$ & $1.02[0.89-1.17]$ & $1.09[0.71-1.68]$ & $1.02[0.77-1.36]$ \\
\hline French & $0.92[0.71-1.20]$ & $1.25[0.98-1.61]$ & $0.86[0.55-1.36]$ & $1.09[0.65-1.84]$ \\
\hline Spanish & $0.89[0.65-1.21]$ & $0.93[0.68-1.27]$ & $1.16[0.67-1.98]$ & $0.49[0.21-1.16]$ \\
\hline Portuguese & $1.13[0.84-1.50]$ & $1.31[1.01-1.72]$ & $0.66[0.38-1.16]$ & $0.77[0.39-1.49]$ \\
\hline \multicolumn{5}{|l|}{ Former } \\
\hline Yugoslavia $^{c}$ & $0.64[0.36-1.15]$ & $0.58[0.40-0.83]$ & $1.76[0.63-4.89]$ & $0.96[0.42-2.16]$ \\
\hline Other, Europe ${ }^{d}$ & $0.85[0.64-1.12]$ & $0.99[0.82-1.20]$ & $1.00[0.60-1.68]$ & $0.91[0.62-1.35]$ \\
\hline Other, World & $0.68[0.43-1.08]$ & 0.76 [0.56-1.03] & $0.85[0.34-2.13]$ & $1.25[0.63-2.50]$ \\
\hline
\end{tabular}


Self-reported dyslipidaemia was defined as a positive answer to the question "Have you ever been told by a doctor that you have high cholesterol?". Results are expressed as the odds ratio and [95\% confidence interval]. BMI, body mass index; PA, physical activity. Statistical analysis by multivariate logistic regression. For the SHS, a further adjustment on the survey was performed. * Caucasians only.

${ }^{a}$ Participants were considered to be normal weight, overweight, or obese if their body mass index was $<25, \geq 25$ and $<30$, and $\geq 30 \mathrm{~kg} / \mathrm{m}^{2}$, respectively.

${ }^{b}$ Considered when the participant reported exercising at least once per week.

c Serbian, Croatian, Bosnian and Herzegovinan, Kosovan and Macedonian.

d Because of the small number of subjects, other nationalities were grouped into either "Other, Europe" or "Other, world". 
Table 6: multivariate analysis of the associations between nationality and the prevalence and management of self-reported diabetes for the Swiss Health Surveys (SHS, 1997, 2002 and 2007) and the Cohorte Lausannoise (CoLaus) study (2003-2006), adjusting for confounding variables.

\begin{tabular}{|c|c|c|c|c|}
\hline & \multicolumn{2}{|c|}{ Prevalence } & \multicolumn{2}{|c|}{ Treatment } \\
\hline & CoLaus, reported & SHS & CoLaus, reported & SHS 2007 \\
\hline \multicolumn{5}{|l|}{ Gender } \\
\hline Female & 1 (ref.) & 1 (ref.) & 1 (ref.) & 1 (ref.) \\
\hline Male & $0.53[0.41-0.67]$ & $0.77[0.70-0.85]$ & $0.40[0.20-0.82]$ & $0.69[0.51-0.93]$ \\
\hline \multicolumn{5}{|l|}{ Age groups } \\
\hline $18-44$ & 1 (ref.) & 1 (ref.) & 1 (ref.) & 1 (ref.) \\
\hline $45-64$ & $2.72[1.80-4.10]$ & $2.41[2.11-2.75]$ & $1.13[0.41-3.14]$ & $2.69[1.71-4.22]$ \\
\hline $65+$ & $5.48[3.52-8.54]$ & $4.99[4.38-5.68]$ & $4.06[1.2-13.71]$ & $4.21[2.74-6.46]$ \\
\hline \multicolumn{5}{|l|}{ Education } \\
\hline Basic & 1 (ref.) & 1 (ref.) & 1 (ref.) & 1 (ref.) \\
\hline Secondary & $1.08[0.79-1.47]$ & $0.75[0.67-0.83]$ & $1.58[0.66-3.75]$ & $0.87[0.60-1.26]$ \\
\hline University & $0.89[0.57-1.40]$ & $0.73[0.63-0.85]$ & 0.36 [0.11-1.13] & $1.07[0.68-1.70]$ \\
\hline \multicolumn{5}{|l|}{ BMI group } \\
\hline Normal & 1 (ref.) & 1 (ref.) & 1 (ref.) & 1 (ref.) \\
\hline Overweight & $1.69[1.22-2.34]$ & 1.64 [1.48-1.82] & 2.49 [1.06-5.85] & $2.16[1.55-3.00]$ \\
\hline Obese & $6.35[4.63-8.73]$ & 3.74 [3.31-4.23] & 4.16 [1.81-9.58] & $4.16[2.81-6.16]$ \\
\hline \multicolumn{5}{|l|}{ Leisure-time PA } \\
\hline No & 1 (ref.) & 1 (ref.) & 1 (ref.) & 1 (ref.) \\
\hline Yes & $0.52[0.41-0.67]$ & $0.73[0.66-0.80]$ & $0.89[0.45-1.76]$ & $0.72[0.53-0.97]$ \\
\hline \multicolumn{5}{|l|}{ Nationality } \\
\hline Swiss & 1 (ref.) & 1 (ref.) & 1 (ref.) & 1 (ref.) \\
\hline German & $1.43[0.55-3.71]$ & $0.76[0.51-1.14]$ & 0.90 [0.09-9.19] & $0.47[0.14-1.61]$ \\
\hline Italian & $1.21[0.81-1.82]$ & $1.01[0.80-1.27]$ & 0.57 [0.17-1.87] & $1.02[0.44-2.39]$ \\
\hline French & $1.00[0.60-1.69]$ & $0.82[0.47-1.40]$ & 0.34 [0.10-1.22] & NA \\
\hline Spanish & $0.93[0.52-1.68]$ & $1.35[0.83-2.20]$ & 0.33 [0.09-1.29] & $0.41[0.07-2.50]$ \\
\hline Portuguese & $0.73[0.39-1.37]$ & 0.86 [0.49-1.52] & $2.98[0.29-30.4]$ & $0.17[0.02-1.59]$ \\
\hline \multicolumn{5}{|l|}{ Former } \\
\hline Yugoslavia $^{c}$ & $1.44[0.63-3.33]$ & $0.82[0.46-1.48]$ & $1.24[0.13-12.3]$ & $0.52[0.10-2.57]$ \\
\hline Other, Europe ${ }^{d}$ & $0.91[0.55-1.49]$ & $0.91[0.64-1.31]$ & $0.71[0.18-2.82]$ & $0.95[0.31-2.94]$ \\
\hline Other, World & $0.50[0.26-0.94]$ & $1.02[0.59-1.75]$ & $0.33[0.08-1.35]$ & $0.90[0.19-4.25]$ \\
\hline
\end{tabular}


Self-reported diabetes was defined as a positive answer to the question "Have you ever been told by a doctor that you have diabetes?". Results are expressed as the odds ratio and [95\% confidence interval]. BMI, body mass index; PA, physical activity. Statistical analysis by multivariate logistic regression. NA, not assessable; *, model did not converge. For the SHS, a further adjustment on the survey was performed.

${ }^{a}$ Participants were considered to be normal weight, overweight, or obese if their body mass index was $<25, \geq 25$ and $<30$, and $\geq 30 \mathrm{~kg} / \mathrm{m}^{2}$, respectively.

${ }^{\mathrm{b}}$ Considered when the participant reported exercising at least once per week.

c Serbian, Croatian, Bosnian and Herzegovinan, Kosovan and Macedonian.

${ }^{d}$ Because of the small number of subjects, other nationalities were grouped into either "Other, Europe" or "Other, world". 